

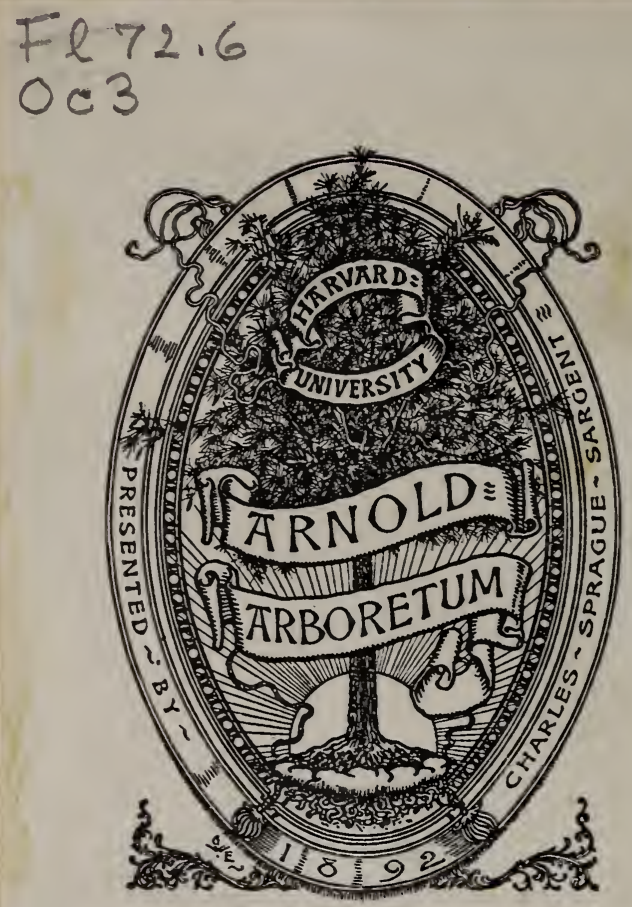


$3 x-0$

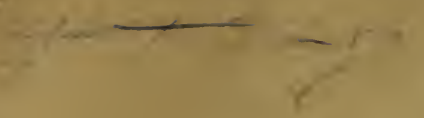
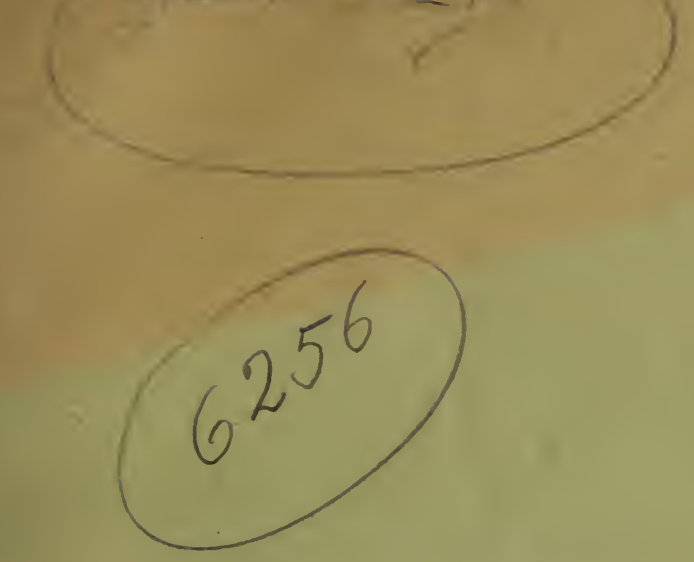

1 




\section{IEGETACIOS RSPONTÁNEA}

$\mathbf{Y}$

\section{REPOBLACION}

DE LOS MÉDANOS

DE LA ZONA LITORAL DE VERACRUZ

INFORME PRESENTADO A IA SECRETARÍA DE FOMENTO

POR EL INGENIERO AGRÓNOMO

IGNACIO OCHOA VILLAGÓMEZ

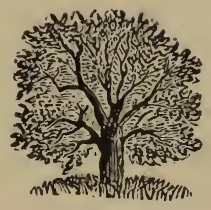

\section{MÉXICO}

OFICINA TIPOGRAFICA DE LA SECRETARIA DE FOMENTO,

Calle de San Andrés número 15.

\section{5}




$$
\begin{aligned}
& \operatorname{Den} 1910 \\
& 23224
\end{aligned}
$$

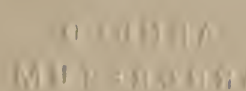



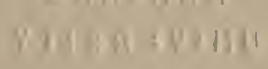


De conformidad con lo dispuesto por esa Secretaría en su oficio relativo, practiqué en las cercanías del puerto de Veracruz las operaciones conducentes al estudio del saneamiento y repoblacion do los médanos inmediatos á aquel puerto. Y como resultado de la comision que recibí, tengo la honra de dar cuenta con el siguiente Informe, al cual acompaño un Herbario, y las colecciones que van detalladas en mi Oficio de remision. 

(2) NTRE las diversas manifestaciones de la accion incesan-
(t) te los mares sobre los continentes, la invasion de los
montículos de arenas arrancadas de la roca y arrojadas á la playa por las olas, es un fenómeno geológico que, con justo motivo, ha llamado en todos tiempos la atencion.

En aquellos sitios en que la costa se levanta erizada de rocas y escarpada, la marea azota y socava los cimientos, ocasionando el derrumbe de enormes masas que las aguas rompen y desmenuzan despues.

No es cierto que estas moles desprendidas de la orilla se depositen para siempre en el Océano; al contrario, desde que caen al mar, son arrebatadas y removidas por la accion combinada del flujo y reflujo, por la fuerza de los vientos ó por las corrientes. submarinas que las tienen en constante movimiento, $y$ las reducen á una extrema division. Sucede así, que los cascajos, arenas gruesas y materias terrosas, en virtud de su mayor peso, concluyen por depositarse en distintos lugares del Océano, en donde encuentran las condiciones necesarias para su estabilidad; pero las arenas finas, como más ligeras, quedan en suspension; son arrastradas por el flujo del mar y por las olas y depositadas sobre las costas más bajas. En cada reflujo queda enjuta aquella orilla, que calienta el sol y el viento impele en seguida hácia los continentes: de tal suerte, que si el hombre no pensara en detener estos montículos movedizos, prontamente cubririan las comarcas y campiñas. 
Con la accion combinada del aire, de la humedad y del tiempo, estas arenas se endurecen mezçándose con los restos animales y vegetales que sorprenden á su paso, formando verdaderas cuestas ó colinas que en frances se llamaron "dunes," y en nuestro país se conocen con el nombre de médanos.

Así es como las dunas del Golfo de Gascuña sepultaron en la arena varias ciudades que figuran en los mapas de la edad média.

Las arenas movedizas de la Arabia desierta producen las constantes trasformaciones que mudan la faz $\mathrm{y}$ el aspecto de sus costas.

Muchas ciudades $y$ aldeas del Egipto han sido invadidas por las arenas del Desierto, desde que la indolencia musulmana no cuidó de contenerlas.

$\mathrm{Y}$ sin ir más léjos, las ruinas de la antigua Villa Rica de la Veracruz, fundada por Cortés, cerca de Zempoala, están actualmente cubiertas por la arena.

Varias circunstancias locales han contribuido poderosamente en nuestras costas del Golfo, $y$ muy principalmente en las cercanías de Veracruz, para formar las dunas ó médanos.

Los primeros regidores de esta villa, no hablan en su carta á Cárlos V, refiriéndose al aspecto de la costa, sino de desiertos arenales; pero probablemente ya existian los médanos en aquella época, aunque no se haya hecho mencion alguna de ellos.

Es bien sabido que, en aquel tiempo, el cordon litoral de Veracruz estaba formado por un arrecife madrepórico ó piedra núcar, que en algunas partes se elevaba á la altura de 1 á 2 metros sobre el nivel de las más altas mareas. Este depósito de coral ha sido ventajosamente empleado como material de construccion, en la fortaleza de Ulúa, en las fincas de la ciudad, en sus baluartes y murallas, y no quedan ya vestigios de él. La aparicion de los médanos en las cercanías de Veracruz, comenzó, quizá, desde que cesó el abrigo que prestaba el arrecife.

Pero prescindiendo de lo que la tradicion ó la Historia nos enseñen sobre este particular, no cabe duda que el litoral de la bahia puede considerarse como un malecon, contra el cual, los vientos dominantes y el perpetuo movimiento de las aguas de Este á Oeste, arrojan sin cesar las arenas que el Océano tiene en suspension. Por otra parte, segun los sondeos y reconocimientos que 
se han practicado, resulta que el perfil del lecho del mar en toda la playa inmediata, favorece notablemente este depósito.

El poder calorífero absorbente de las arenas y su extrema tenuidad, prestan ocasion á los vientos para arrebatarlas y removerlas, formando con ellas montículos movedizos más ó ménos elevados.

Experimentan notables trasformaciones estas pequeñas colinas en la época de los equinoccios, y en los meses de Octubre á Marzo en que reinan los vientos impetuosos llamados "Nortes." Ocupan dilatadas extensiones, conservando las huellas del viento que las ha impelido; y como dice Bremontier, refiriéndose á las dunas del Golfo de Gascuña, "pudieran compararse al aspecto de un mar embravecido, cuyas encrespadas olas fuesen súbitamente fijadas, en medio de una tempestad."

En la parte expuesta al viento reinante, la pendiente de los médanos es suave y no excede de 25 á 30 grados: no sucede otro tanto al lado opuesto, en donde las arenas que llegan á la cima y la rebasan, se deslizan en virtud de su propio peso, tomando la inclinacion que corresponde á su talud natural, y que, como el cálculo indica, es de $34_{2}^{\frac{1}{2}}$ grados. Algunos médanos alcanzan la altura de 50 y aun 80 metros sobre el nivel de la playa.

La configuracion de estas costas va cambiando, como debe suponerse, porque variando de lugar los médanos, cambian tambien de sitio los valles y cañadas que están entre ellos comprendidos.

En la estacion de las lluvias, aquellos bajos se trasforman en pantanos y pequeños lagos, en donde, los restos orgánicos entran prontamente en descomposicion bajo los rayos ardientes de un sol ecuatorial, y mantienen una atmósfera húmeda y saturada de miasmas, muy nociva á la salubridad: á esta circunstancia se añade la influencia malsana de los desechos marinos que arrojan las olas á la playa, y los cuales entran tambien en putrefaccion muy fácilmente.

Por otro lado, ese constante vaiven de las arenas impide dar salida á aquellas aguas estancadas, porque cubririan los canales y sepultarian las obras de construccion que con tal objeto se emprendieran.

La zona litoral se eleva á unos 162 metros (500 piés) sobre el nivel del mar, y se extiende en llanadas ó sabanas arenosas, en- 
trecortadas por los médanos que forman pequeñas cordilleras, cuyas faldas se inclinan suaremente hácia la playa.

El período de las lluvias es allí de cinco meses, desde Junio hasta Noviembre, $y$ la cantidad de agua que cae anualmente es de $1^{\mathrm{m}} 62$ por término medio. En el resto del año, el vapor de agua llevado en suspension por los alisios no llega á precipitarse: de un lado, la elevada temperatura producida por la posicion zenital del sol, $y$ por otro la influencia de las montañas vecinas, se combinan para dar este resultado.

En el invierno, hay que agregar otra causa de major importancia: sucede en efecto con frecuencia, de Octubre á Marzo, que el viento Noroeste del Golfo se interrumpe por los "Nortes," que no son otra cosa que una desriacion del alisio, producida por la aspiracion que las costas bajas de la península de Yucatan ejercen, á la manera del tiro de una inmensa chimenea. Las ráfagas ó bocanadas de este aire frio que se desprenden de la bahía de Hudson, atraviesan el Canadá y la parte oriental de los Estados Unidos, se saturan de vapores en las aguas del Golfo, $y$ vienen despues á descargarse con extraordinaria riolencia sobre el paralelo de Veracruz y de la Habana; pero como se encuentran con capas de aire muy caliente, su punto de saturacion se retrasa, y no alcanzando á resolrerse en lluvia, sólo refrescan la temperatura.

Estas conmociones atmosféricas se anuncian por una violenta perturbacion en la marcha del barómetro.

Casi siempre, un stratus, cuyo perfil aparece al Norte, dibujado en lontananza á la manera de una oscura faja, es el precursor seguro de este fenómeno imponente.

Sopla al principio un viento ligero de tierra; se experimenta un calor sofocante; en seguida sopla brisa; la cima del Citlaltepetl se proyecta sobre un cielo azul y despejado, al mismo tiempo que oculta su falda entre un velo vaporoso $y$ trasparente. La humedad se precipita á manera de rocío sobre el empedrado de las calles, en las barandillas de los balcones y en los objetos de madera y fierro. En tales circunstancias, el fenómeno comienza. La tempestad se desata. Levanta el mar sus encrespadas olas, que baten con furia sobre los muelles y salvan á reces la muralla. La comunicacion con el castillo de Ulúa se interrumpe. Las embarcaciones cortan sus amarras y huyen á alta mar, ó van á bus- 
car abrigo detrás del inmediato islote de Sacrificios. La duracion del fenómeno se prolonga por dos, cuatro y aun ocho dias.

Otra de las circunstancias que influye poderosamente en el clima de Veracruz, es la corriente marítima llamada el Gulf-Stream, que desde que entra en el Golfo de México, corre paralelamente á nuestras costas y voltea por la punta de la Florida para dirigirse á Terranova.

Bastará fijarnos en que el agua es el cuerpo que posee la mayor capacidad calorífica, para comprender que la circulacion constante é inmediata de esta inmensa masa de agua caliente, es no solamente un foci activo de calor, sino tambien la causa incesante de vapores, cuyos efectos deberán hacerse sentir desde luego sobre las costas y en seguida en la tierra firme. Se debe tambien á la presencia de esta corriente, el depósito constante que deja el mar sobre sus orillas.

Está situado Veracruz á los $19^{\circ} 11^{\prime} 30^{\prime \prime}$ de latitud Norte, y á los $2^{\circ} 46^{\prime} 56^{\prime \prime}$ de longitud Este del meridiano de México.

En la estacion del verano sube la temperatura máxima hasta $35^{\circ}$ del termómetro centígrado, y la mínima llega á $25^{\circ}$, siendo de $29^{\circ}$ la temperatura média en este período del año.

En el invierno, la temperatura máxima oscila entre $20^{\circ}$ y $24^{\circ}$, y la mínima llega hasta $12^{\circ}$, resultando entónces de $18^{\circ}$ á $19^{\circ}$ la temperatura média.

Dominan en los meses de Marzo y Abril, con la velocidad ordinaria de 8 á $11^{\mathrm{m}}$ por segundo, los vientos fuertes del Sur. Des. de el mes de Diciembre hasta el de Febrero sopla comunmente el S.E., y en seguida el Norte, que lo hace á veces con la velocidad de $19^{\mathrm{m}}$ por segundo, y está ordinariamente cargado de ozono.

Del mes de Mayo á Noviembre reina el alisio del S.E., durante el dia, y la brisa del N.O. en la noche.

La presion atmosférica média es casi la altura barométrica que corresponde al nivel del mar, es decir, $0^{\mathrm{m}} 762$.

El higrómetro indica generalmente, dụrante los "Nortes," la humedad relativa de 0.80 á 0.86 por término medio.

Por último, la declinacion magnética es de $\tau^{\circ} 2 \tau^{\prime}$ hácia el Este

Estos datos, unidos á lo que anteriormente dejo apuntado, podrán servir para estudiar la distribucion de las diversas especies 
vegetales, en las que la influencia del clima depende más bien de las temperaturas extremas que de la temperatura média.

Pasados algunos momentos, despues que ha soplado un Norte, es cuando la zona litoral de Veracruz es digna de estudiarse.

Desde luego, la parte azotada por el viento presenta á la vista el cuadro de una lucha, sostenida por una raquítica regetacion contra el elemento destructor.

Las huellas del viento se ven impresas en las ondulaciones que la arena ha conservado.

La vegetacion poco densa y elerada, se compone principalmente de rarios géneros de Gramíneas, como el Cenchrus racemosus, de espinoso cáliz; el Eragrostris reptans, de enrolladas hojas, y cuyas raíces capilares que nacen de cada nudo, se adhieren en la arena como los tentáculos de un molusco.

La C'assia recumbens, de hojas bipenadas y pequeñísimos foliolos, que esconde sus delicadas flores en la arena.

Otros diversos grupos de plantas herbáceas, entrelazados con malváceas del género Sida, y breñales de Acacias y Mimosas de gruesas espinas. Algunos matorrales en que descuella el Brometia pinguin, euyas bojas rígidas, armadas de algunas puntas en su orilla, parecen adaptarse muy bien al clima reseco de la costa; pero lo que principalmente caracteriza la vegetacion de esta parte de los médanos, son algunos tipos de la familia de los Palmeros y de las Cacteas, que tambien resisten los rigores del clima.

Examinando más detenidamente la regetacion espontánea de esta parte de la zona, se distinguen las especies siguientes, cuyos ejemplares pude colectar $y$ figuran en el Herbario que va adjunto al presente Informe: 
Gramíxeas.

Cenchrus racemosus (rosetilla)

Eragrostis reptans.

Leersia mexicana.

Poa rariflora.

LEGUMixosas.

Cassia chamacristoides.

Acacia cornígera.
Malváceas.

Sida Cordifolia.

Malva scoparia.

Bromelí́ceas.

Bromelia pinguin (Timbiriche).

Palmeros.

Coccus guacuyule (Palma coyol).

Cacteas.

Cactus opuntia.

La familia de las umbelíferas está representada allí por el $H y$ drocotile umbellata, que abunda en los puntos húmedos y sombríos.

Las Comelíneas, por la Commelyna tuberosa, cuyas moradas flores matizan el tapiz que forman las gramíneas.

Las Cyperáceas están representadas por algunas especies pertenecientes á los géneros Carex, Ciperus y Scirpus, que pueden verse tambien en el Herbario.

Y por fin, flotan en la orilla del mar ó son arrojadas por las olas á la playa, las Cryptógamas siguientes:

La Dictiota ciliata, la Dictiota fasciola y la Dictiota bastagresiana con la Padina pavonia.

El Sargassum montagnei, de grandes esporos.

El Memation multifidum y el Halimeda opuntia, que arrojan los vientos á la orilla.

Con más riqueza de formas y mayor variedad en las especies, se presenta la vegetacion en la parte Sur de los médanos, abrigada de los vientos. Las formas tropicales adquieren allí su entero desarrollo.

Esta porcion interior de la zona tiene un tapiz de gramíneas, entre las que descuellan el Buchlo dactyloides ó Buffalo-gras, que abunda en las praderas americanas.

Se distinguen tambien las especies siguientes, cuyo carácter geográfico depende indudablemente de la direccion de los vientos reinantes: 
Gramíneas.

Paspalum conjugatum.

Eleusine indica.

Cynodon dactylon.

Chloris distachya.

Leptochloa filiformis.

Las especies de otras familias que imprimen una fisonomía particular á la region de esta zona litoral, son la forma desarrollada de los Palmeros, la del Ficus sicomorus, el Guarea ramiflora ó palo corado, el Palo mulato y diversas Rosáceas y Mimosas arborescentes.

La aglomeracion de vegetales leñosos y la abundancia de parásitos ó epifitos, y las lianas que adornan el tronco de los ảrboles, le comunican un aspecto enteramente tropical.

Algunas Aroideas, Scitamineas y Helechos que crecen á la sombra, aumentan notablemente las dimensiones de su follaje.

Las siguientes especies que aparecen en el Herbario, son:

Leguminosas.

Hedysarum flexosum.

Abrus precatorius.

Erikcriva coraloides.

Malváceas.

Las de la region anterior, y además

Malvaviscus coucinus.

Anoda-hastata.

Bombáceas.

Pachira fastuosa.

Meliáceas.

Guarea ramiflora.

Melia azederach.

$$
\text { Vitíceas. }
$$

Vitis silvestris.

Lantana aculeata.

Asclepiadeas.

Asclepias curassavica.

Auranciáceas.

Citrus medica.

ANACARDIÁCEAS.

Mangifera indica.

Papateríceas.

Argemone mexicana.
Scitamíneas.

Canna indica.

Papayáceas.

Carica papaya.

Solaneas.

Solanum marítimum.

Convolyuláceas.

Convolvulus arvensis.

$$
\text { HeLECHOS. }
$$

Cænopteris achillæfolia.

Compuestas.

Palafoxia Lindenii.

Mikania denticulata.

II. Houstonii.

Bidens pilosa.

Amarantáceas.

Gomphrena globosa.

Ranunculáceas.

Clematis Gæricea.

$$
\text { Gramíneas. }
$$

Arundo nitida. 
En las orillas de los pantanos ó lagunas interpuestas entre los médanos, se distinguen comunmente las siguientes:

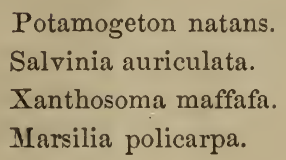

Debo mencionar, además, otras especies que no pude colectar por no haberlas encontrado en florescencia, y que son, sin embargo, de la mayor importancia en el estudio de la flora de esta region litoral.

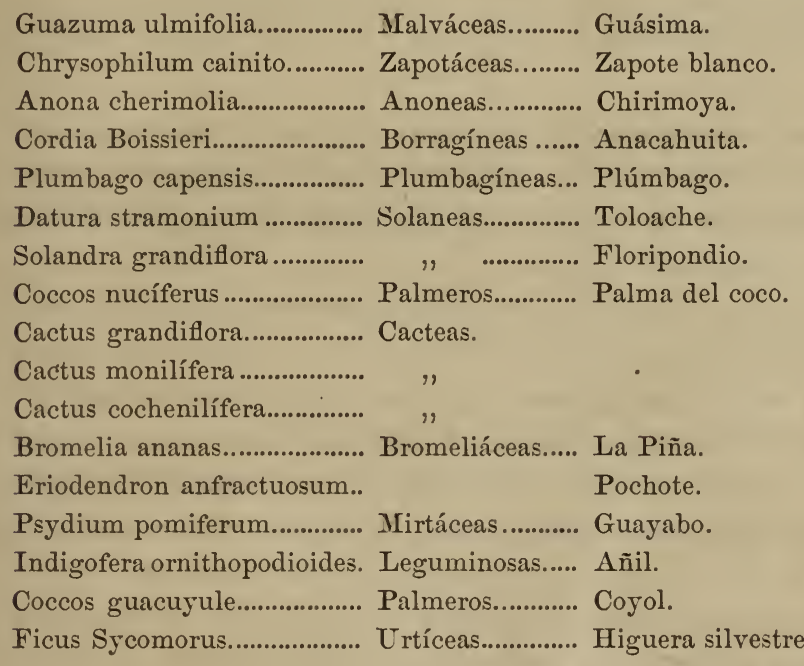

El distinguido naturalista Mr. E. Fournier, que sin disputa posee el Herbario más completo de nuestra Flora mexicana, se ha ocupado tambien de la vegetacion de esta region litoral del Golfo, $\mathrm{y}$ cita las especies siguientes: 
GRAMÍNEAS.

Dactyloctenium ægiptiacum.

Hemarthria fasciculata.

Oplistemenus.

Stenotaphrum americanum.

Eragrostis Vera-crucis.

Leersia Gonini.

Trachypogon Gonini.

Agrostis virginica,

EUFORBIÁCEAS.

Croton rivinofolius.

C. reflexifolius.

C. cortesianus.

CONVOLVULÁCEAS.

Convolvulus palustris.

C. Germanniæ.

C. Rosiflorus.

Caliptigia soldanella.

\section{LEGUMINOSAS.}

Tephrosia litoralis.

Desmodium arenarium.

Rhynchosia menispermoides.

AMARANTÁCEAS.

Amaranthus spinosus.

Iresine diffusa.

Gomphrena interrumpta.

ACANTÁCEAS.

Cryphiacanthus barbadensis.

Dipteracanthus procumbens.

Adhatoda dipteracantha.

AMEXTÁCEAS.

Celtis litoralis.

Platanus Liebmanni.

Justamente sorprende que una vegetacion tan vigorosa y que reviste tanta riqueza en las formas como variedad en las especies, se levante en un terreno que á primera vista parece estéril é impropio para todo cultivo.

Aquellas arenas, de algunos metros de profundidad, extremadamente finas, susceptibles de moverse al menor soplo del viento, no se creeria que fuesen á propósito para dar asiento $\mathrm{y}$ vida á aquella diversidad de plantas herbáceas y árboles de grande talla; pero estudiándolas con más detenimiento se podrá descubrir que poseen, entre otras propiedades, la de absorber el vapor de agua que habitualmente existe en bastante cantidad en el aire en aquel clima, de tal manera, que á la profundidad de $0 .{ }^{\mathrm{m}} 15$, se conserva siempre cierto grado de humedad que es muy favorable á la germinacion y crecimiento de las plantas.

Absorben además estas arenas las sustancias orgánicas y sales amoniacales contenidas en la atmósfera, las retienen entre sus partículas y las proporcionan despues segun las necesidades de la vegetacion.

Examinadas al microscopio, se presentan compuestas estas arenas de cristales de cuarzo, de fragmentos oscuros de hornblenda y de algunos átomos de carbon de piedra. 
Se descubren además unas granulaciones blanquizcas, unidas entre sí, formando grupos ó mallas, y depósitos de restos orgánicos de pólipos, moluscos y foraminíferos en sus diversas formas.

El análisis químico, aunque practicado de una manera imperfecta y apénas aproximado, viene no obstante confirmando el reconocimiento microscópico anterior, porque en 100 partes de esta arena se encuentra la siguiente composicion:



La presencia de los restos orgánicos $\mathrm{y}$ el fosfato de cal en estas tierras, así como las propiedades físicas que dejo apuntadas, nos explican suficientemente la variada y vigorosa vegetacion de que están cubiertas, favorecidas por el clima tropical en que se encuentran.

De sentirse es que el puerto de Veracruz, el más importante y concurrido de todos los de la República, reuna á los graves inconvenientes de un mal fondeadero las condiciones malsanas de nuestras costas del Golfo, y además el azote del vómito ó fiebre amarilla, á los que están expuestos, sobre todo, los extranjeros y personas no connaturalizadas con el país. $\mathrm{Y}$ mucha razon ha habido por parte del Supremo Gobierno y del Municipio de Veracruz para tratar de combatir las causas de insalubridad de este puerto.

Sin pretender averiguar cuál pueda ser el rerdadero orígen del vómito, sólo llamaré la atencion sobre esta circunstancia: todos los que se han ocupado de esta cuestion interesante convienen en que la enfermedad aparece y comienza á propagarse cuando concurren ciertas condiciones de humedad, de calor y de impureza en la atmósfera, que se producen en determinada época del año: todas ellas están subordinadas al clima de aquel lugar y aun podria decirse que lo caracterizan; por consiguiente, todo aquello que tienda á mejorarlo, producirá necesariamente sus efectos en el mismo sentido respecto de la salubridad. 
El cambio de sitio de los médanos y de las arenas movedizas, que todo lo invaden; los pantanos que se forman con el agua de las lluvias en los pequeños valles ó cañadas, y que se convierten en focos de emanaciones malsanas, todo ha indicado que para mejorar las condiciones climatológicas se deberá comenzar por contener las arenas arrojadas á la orilla, y repoblar y sanear los médanos despues.

Para lograr lo primero empleó Bremontier con muy buen éxito, cerca de Burdeos, fajinas ó tablones fijados á pilotes ó maderos, y colocados paralelamente á la orilla del mar, con la altura conveniente para detener las invasiones de las primeras arenas; y para conseguir lo segundo emprendió con no ménos éxito la repoblacion de las dunas de Burdeos, con plantaciones de pino marítimo; obras que justamente han inmortalizado su nombre.

Una vez que tal sistema ha producido tan excelentes resultados, se ha tratado de imitar, y para poderlo adaptar al clima y necesidades de Veracruz, sólo se discute sobre las especies vegetales que más convengan á aquel lugar, ya que el pino marítimo no ha podido prosperar.

Aconseja el Sr. Hübbe, inspector de las dunas de Keitum, el empleo de la caña de médano, Arundo arenaria, para fijar las arenas de la playa.

El Sr. Juan F. Ramos, en un trabajo inédito que sobre este particular escribió, da útiles consejos sobre los mejores métodos de cultivar algunas plantas en los arenales, $y$ es de opinion (aunque confiesa que no conoce el clima de Veracruz) que podria ensayarse la plantacion de varios árboles resinosos y balsámicos, que espontáneamente crecen en la isla de Pinos.

Otros autores que se han ocupado de este mismo asunto, recomiendan para la repoblacion de los médanos de Veracruz diversas plantas de rápido crecimiento, y citan el eucalyptus, el laurel de las Indias, la ceiba y otros varios.

Cuestiones son éstas que no pueden resolverse sin tener á la vista el estudio minucioso del clima y condiciones geológicas de la localidad.

Hé aquí el motivo por que esa Secretaría ha dispuesto acertadamente que ántes de emprender un trabajo serio en ese sentido, 
se comience por explorar y estudiar aquella parte de la zona litoral del Golfo.

No es mi ánimo contradecir la opinion autorizada de personas tan competentes en la materia de que se trata, y sólo me limito á exponer la mia, fundándola en los datos que he ido á recoger en la misma localidad.

Los centros de vegetacion no están repartidos al acaso y de una manera caprichosa, como pudiera creerse á primera vista: se observa siempre en su distribucion la obediencia á ciertas leyes inmutables que presiden á la variedad de las especies, y de aquí precisamente se derivan los principios que han servido de cimiento á una nueva ciencia que se llama Geografía Botánica.

Cada especie vegetal tiene una patria determinada, y cuando se propaga no lo hace sino dentro de los límites que la naturaleza inorgánica le fija, y sin quebrantar jamas los vínculos que ligan el organismo vegetal al mundo físico de que está rodeado.

No basţa que el suelo adonde una planta se trasporta, contenga en su composicion todos los elementos necesarios para su nutricion: es necesario tambien que el clima por su parte no oponga obstáculo alguno para su perfecto desarrollo.

$\mathrm{Y}$ como la determinacion del clima de un lugar es una cuestion complexa que depende de su latitud, de su altura sobre el nivel del mar, de su temperatura, de sus accidentes topográficos, vientos dominantes, etc., etc., cada una de estas circunstancias tiene que influir muy directamente, no sólo en la fisonomía de la vegetacion, sino tambien en la distribucion de las especies.

En comprobacion de lo que acabo de decir, se observa en nuestro país, hácia el lado del Golfo y sobre el $19^{\circ}$ paralelo en que Veracruz está situado, la siguiente sucesion de zonas vegetales muy bien marcadas:

Partiendo de la playa con direccion á los Andes mexicanos, la region tropical se eleva hasta los 1,949 metros sobre el nivel del mar.

Desde esta altura hasta los 2,534 metros, se extiende la region forestal de los encinos, y comienza allí mismo la de las coníferas, que se eleva hasta los 3,996 metros sobre el nivel de los mares.

A los 4,515 metros se encuentra generalmente el límite de las nieves perpetuas. 
Cierto es que el carácter mixto de formas vegetales, carácter peculiar de las montañas mexicanas, se presenta en la region forestal que reune los encinos á las formas arborescentes del clima tropical. Muy cierto es tambien que en las inmediaciones de Orizaba, á unos 649 metros de altura, los encinos siempre rerdes revisten una gran parte de la region montañosa, y se ven confundidos con algunos representantes del laurel y otros pertenecientes á las cycádeas y myrtáceas.

Pero no se podrá señalar otro caso, que el muy raro del Joru1lo, en cuyos flancos se ha encontrado el Pinus oocarpa á 600 metros de altura, y nunca se ha observado en nuestro país que estas coníferas desciendan hasta las playas.

Mucho llama la atencion ciertamente el caso excepcional que se presenta en Cuba y en Haiti, de que los pinos bajen hasta la region cálida de la costa, y crezcan allí confundidos con la Caoba y los Palmeros; miéntras que en México, no dan un paso fuera de los límites de su zona, y no se les encuentra sino desde los $975 \mathrm{me}$ tros de altura sobre el nivel del mar; y no obstante, las especies son tan próximas, que se les habia refundido con el nombre de Pinus Occidentalis.

El pino que habita las costas bajas y calientes de Nicaragua, es el mismo que en la isla do "Pinos" es compañero de la Caoba, y el mismo tambien que en México jamas desciende de la altura mencionada. Fenómeno notable, que sólo puede explicarse por los contrastes que por causa del clima se producen entre especies muy próximas.

Hay, en efecto, poca concordancia entre el clima de las costas de Teracruz y el de la isla de Cuba, por más que las latitudes sean poco diferentes; pero como ántes he dicho, la latitud no es el único factor, ni el que más influye en la determinacion de los climas.

De todo lo expuesto, deduzco lo siguiente:

Que la repoblacion de los médanos de Teracruz no puede hacerse por medio de la regetacion forestal; y que debemos limitarnos á elegir para este objeto las especies más convenientes de la Flora tropical.

De poco tiempo á esta parte, algunos autores, sobre todo los agrónomos alemanes, vienen recomendando las especies de la fa- 
milia de las Casuarinas de Australia, como las plantas más adecuadas para repoblar los arenales de las orillas del mar; asegurando que se ha obtenido el éxito más completo en todos los trabajos de estę género que con ellas se han emprendido.

Se les llama así, porque los verticilos ó mechones de hojas aciculares que tienen estas plantas en los nudos del talle, dan una idea del plumaje del Casoar; pero son parecidas por su parte á las que nosotros conocemos vulgarmente con el nombre de "colas de caballo" [Equisetum].

No tienen expansiones foliáceas, y la superficie de sus órganos está cubierta de una epidermis densa, rígida é incolora, que sirve para limitar la eraporacion de la sária. Protegidas así las hojas, al abrigo de las variaciones producidas por el cambio de las estaciones, pueden conservarse mucho tiempo sin necesidad de renovarse por medio de botones; de tal suerte, que miéntras las demas plantas aprorechan la estacion húmeda para retener el agua en sus tejidos y prolongar así el período de su desarrollo, las Casuarinas se estacionan en su crecimiento si la sequedad del Estío las sorprende. Aprovechan la humedad de la lluvia cuando la has, y continúan creciendo miéntras experimentan su efecto, sin tener necesidad de preparar nueros botones, porque los órganos antiguos quedan intactos.

Los otros regetales son de climas periódicos. Las Casuarinas prosperan con la humedad eventual, y segun ésta sea, escasa ó abundante, así se las ve crecer ó estacionarse.

En una palabra, son la expresion más sencilla de una planta que se adapta perfectamente á un clima que exige lento desarrollo y susceptible de ser interrumpido.

Desde luego se echa de ver que por esta circunstancia, quizá pudieran emplearse rentajosamente, $\mathrm{y}$ se adaptarian al clima de la zona litoral que nos ocupa.

Yo encontré en la isla de Sacrificios una especie de arundo ó caña, el "arundo nitida," cuyo ejemplar puede verse en el Herbario.

Cubre esta gramínea gran parte de la isla, y crece allí espon- 
táneamente por supuesto. Su nudosa rizoma, que se propaga de una manera extraordinaria, se extiende formando una red ó malla, la más á propósito para contener y fijar las arenas.

Pues bien, yo aconsejaria que en lugar del "arundo arenaria" que el Sr. Hübbe propone para este objeto, se empleara este otro, que con ménos gastos y más probabilidades de buen éxito, se puede tomar de la misma localidad.

Tambien es mi opinion que una vez contenidas las primeras invasiones de la arena, por medio de fajinas colocadas paralelamente á la orilla del mar, y á unos 40 ó 50 metros de distancia del límite de las aguas, se proceda al plantío de la primera zona vegetal con esta gramínea, que servirá de parapeto $\mathrm{y}$ abrigo á la zona siguiente. Las nuevas arenas que salgan del mar para perjudicarlas, serán retenidas por el cordon de fajinas, cuya altura podrá aumentarse si fuere necesario, y con ellas mismas se formará en poco tiempo un valladar, que impedirá á las siguientes salir fuera de la playa, siendo ar'rastradas al mar por el ímpetu de las olas. Esta lucha continua vendrá á producir necesariamente una modificacion en el perfil del cordon litoral, cada dia más favorable al objeto que uno se propone.

Se formará la segunda zona ó faja, con plantas de vegetacion rastrera y de rápido crecimiento, con las diversas especies de gramíneas que nacen allí espontáneamente, entremezclándolas con sembrados esparcidos á largos trechos, de Mimosas de gruesas espinas y Malváceas del género Sida. Esta zona podrá tener unos 60 metros de ancho.

Dado este primer paso, fácil seria despues proceder á la plantacion de árboles de mayor talla, escogidos entre las especies que son comunes allí, y cuya monografía va detallada en el presente Informe.

Plantada la segunda zona, se plantará la tercera, y así sucesivamente, cuidando de no dejar ningun vacio sensible entre ellas, sino que queden contiguas unas á otras.

Las especies que para este objeto deben preferirse, son, en mi concepto, la forma Sicomorus ó Higuera silvestre, el Palo mulato, el Palo colorado, Guarea ramiflora, el Celtis littoralis, el Jatropha y algunas otras tomadas entre las familias de las Cácteas, Cycádeas, Mirtáceas y Amentáceas, que se desarrollarian y crecerian 
tanto más rápidamente, cuanto que la naturaleza y clima de aquel suelo les es muy farorable.

Aparte de las inapreciables ventajas que la repoblacion de los médanos produciria, mejorando desde luego las condiciones de salubridad del puerto de Veracruz, se podria tambien, una rez fijadas las arenas, abrir algunos de aquellos terrenos al cultivo, lo cual aumentaria notablemente su ralor. Se sabe muy bien que son aptos para todo género de produccion agrícola, sin necesídad de abonos ó correctiros, $y$ sin que sea necesario recurrir al "año y vez" ó á cualquier otro sistema de rotacion. En una palabra, estos ricos terrenos pueden conservar por un largo período de años una fertilidad inagotable; y aun cuando los rendimientos disminuyeran, se tendria en el empleo de los "rarechs, desechos marinos é inmundicia de la ciudad, un recurso ilimitado.

Presentan todavía otras ventajas: pues 'segun su composicion mixta, en la que el elemento calcáreo y el arenoso existen en proporcion conveniente, son poco sensibles á las variaciones atmosféricas; su grande profundidad y la frescura del subsuelo, los hacen á propósito para la regetacion de plantas de raíces largas y pivotantes como la alfalfa y otras, cuyas cosechas alcanzarian el máximum de su rendimiento.

Allí se cultivarian, sin duda con buen éxito, la morera y la vid, la caña de azúcar y el añil, que crecen espontáneamente y en estado silvestre.

Creo, con lo expuesto, haber dejado desempeñada la comision que se me encomendó; $\mathrm{y}$ terminaré, deseando vivamente que se ponga en práctica aquella obra, sobre cuyo carácter de utilidad pública y privada no podrá suscitarse duda alguna.

México, Agosto 18 de 1884.

IgNacio OGHOA Villagómez. 



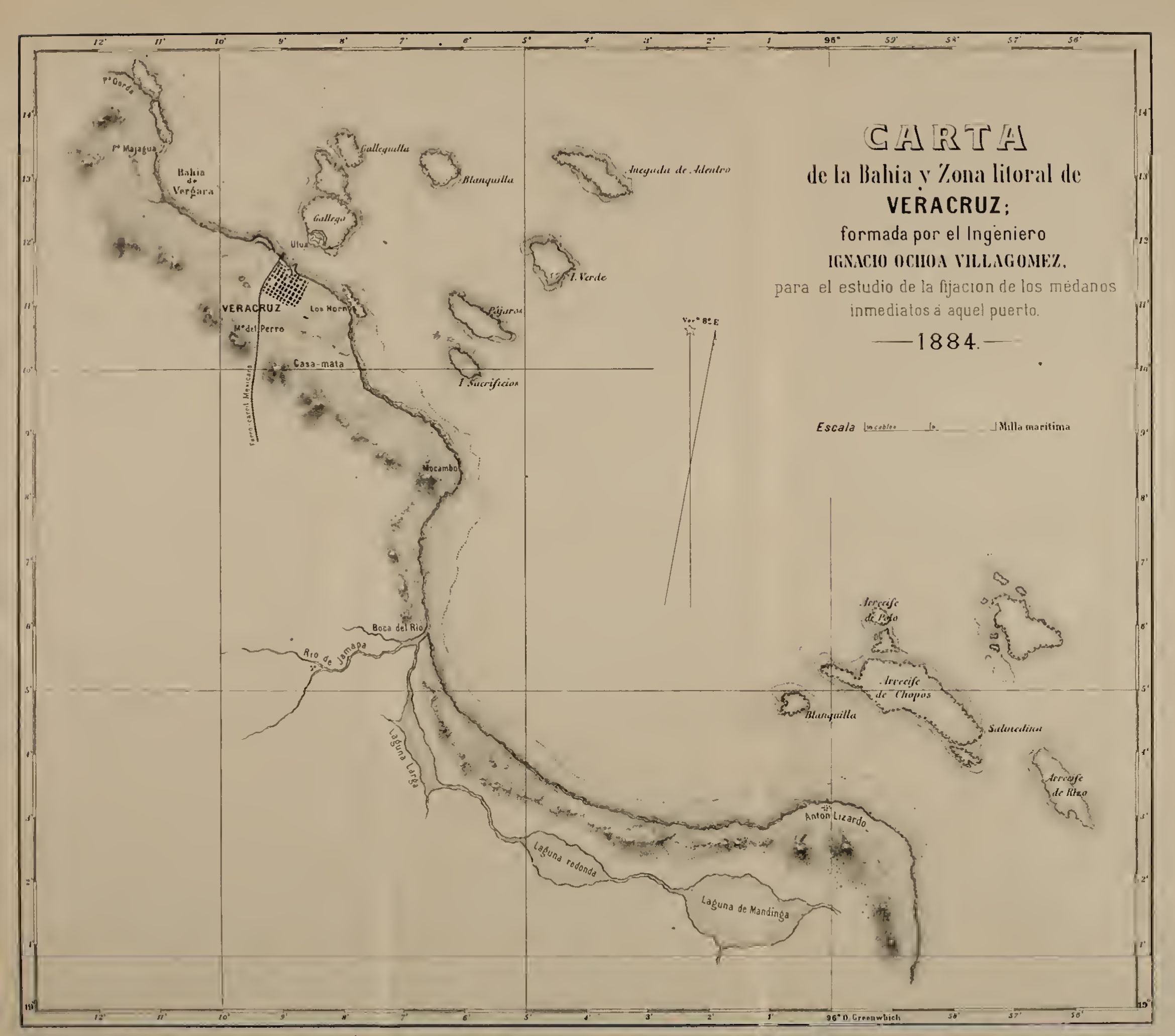





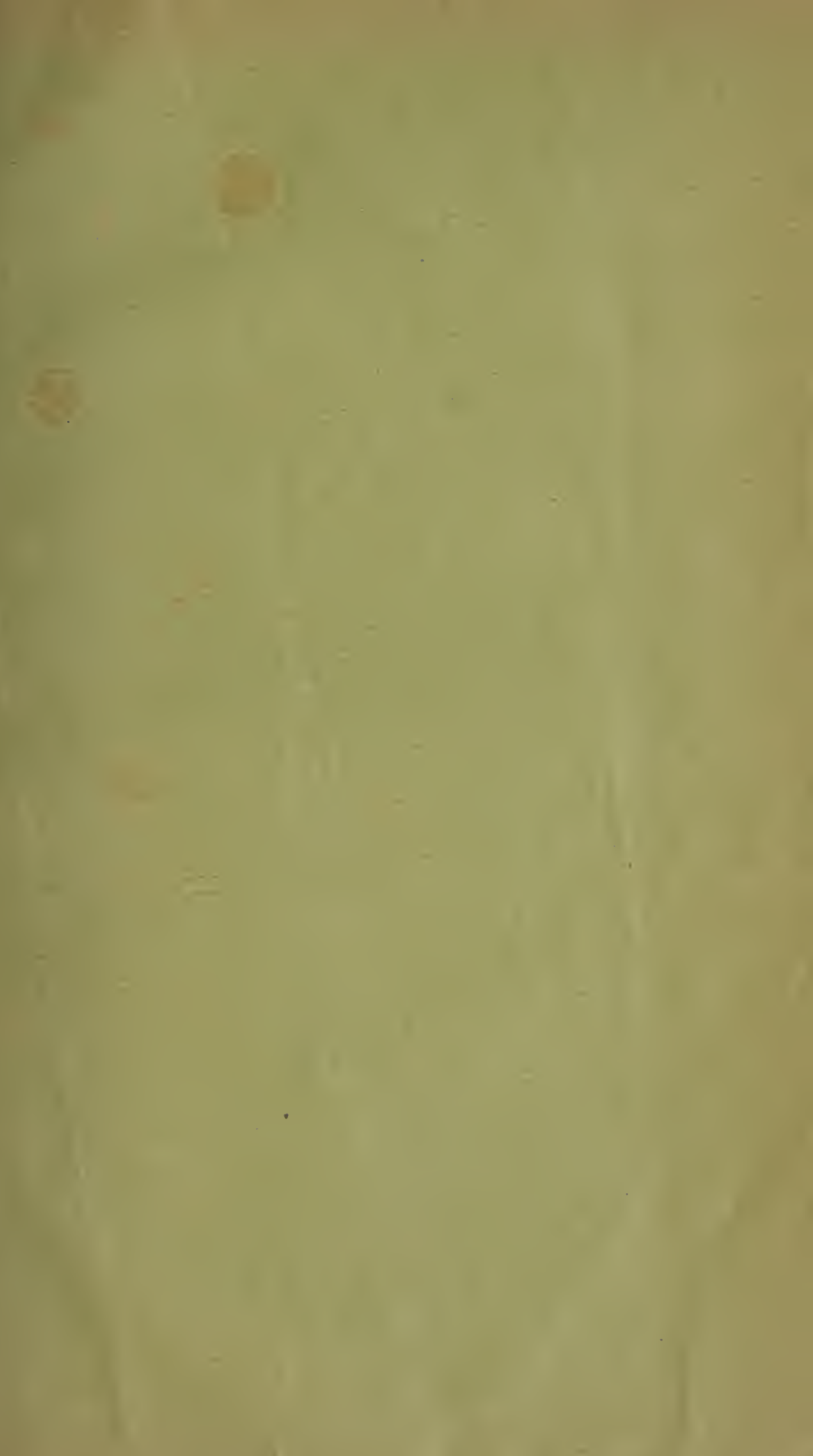




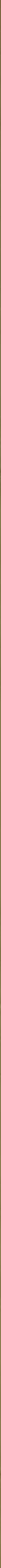



